\title{
La visión de la bandera. Memorias oníricas awajún sobre la construcción de una sociedad de frontera en la Amazonía peruana*
}

\section{Resumen}

El presente artículo busca comprender de qué forma la labor pedagógica, realizada por los religiosos evangélicos en la mitad del siglo $\mathrm{XX}$, desempeñó un importante papel "civilizador" y de "formación ciudadana" dentro de la sociedad indígena awajún presente en la frontera nororiental de la Amazonía peruana. Dicha labor marcó no solamente el proceso de ampliación de las fronteras estatales sino, sobre todo, un cambio importante dentro de la percepción de la realidad que los mismos awajún comenzaron a adoptar, aspecto visible en muchas de sus expresiones cotidianas (ej. el lenguaje onírico) y también en sus nuevas formas de representación del poder. En tal sentido, se advierte el inicio de un proceso de asimilación de la figura profesional del "profesor bilingüe" a la categoría mayor de "hombre fuerte" entre los awajún, aspecto que va acompañado de la elaboración de un nuevo lenguaje visual e imaginativo.

\section{Palabras claves}

Tesauro: Amazonía, Perú, frontera, religión.

Autor: indígenas, memorias.

Referencia bibliográfica para citar este artículo: Romio, Silvia. "La visión de la bandera. Memorias oníricas awajún sobre la construcción de una sociedad de frontera en la Amazonía peruana”. Anuario de Historia Regional y de las Fronteras 25.2 (2020): 69-90.

Fecha de recibido: 3/12/2019

Fecha de aceptación: 27/02/2020

Silvia Romio: Doctora en Estudios Políticos por la Escuela de Altos Estudios en Ciencias Sociales de París. Profesora en la Pontificia Universidad Católica del Perú. Investigadora asociada al IFEA (Instituto Francés de Estudios Andinos). Código ORCID: 0000-0002-5287-2383. Correo electrónico: silvia. romio@gmail.com.

*El presente artículo ha sido realizado gracias al proyecto de investigación: "Configuraciones socioespaciales, retos políticos y debates ontológicos en la Amazonía”, proyecto financiado por la Agencia Nacional de la Investigación (ANR-17-CE41-0013- Francia). 


\title{
The Vision of the Flag. Awajun Oneiric Memories about the Construction of a Frontier Society in the Peruvian Amazonia
}

\begin{abstract}
This article attempts to understand how the pedagogical work carried out by evangelical priests in the middle of the 20th century played an important "civilizing" and "citizen education" role within the Awajun indigenous society which was present on the northeast border of the Peruvian Amazonia. Such work marked, not only the process of expanding state borders, but also and more importantly, a crucial change within the perception of reality which the Awajun themselves began to adopt, a visible aspect in many of their daily expressions (e.g. oneiric language) and also in its new forms of representing of power. In this sense, there is the beginning of a process of assimilation of the professional figure of the "bilingual teacher" to the greater category of "strong man" amongst the Awajun, an aspect that is accompanied by the elaboration of a new visual and imaginative language.
\end{abstract}

Keywords

Thesaurus: Amazonia, Peru, Border, Religion.

Author: Indigenous, Memories.

\section{A visão da bandeira. Awajun memórias oníricas sobre a construção de uma sociedade de fronteira na Amazônia peruana}

\section{Resumo}

Este artigo visa entender como o trabalho pedagógico realizado pelos religiosos evangélicos na metade do século $X X$ desempenhou um importante papel "civilizador" e de "formação cidadã" dentro da sociedade indígena Awajún presente na fronteira nordeste da Amazônia peruana. Este trabalho religioso marcou não só o processo de expansão das fronteiras estatais, mas, sobretudo, uma importante mudança na percepção da realidade que os próprios Awajún começaram a adotar, como resulta demonstrado em muitas das suas expressões diárias (por exemplo, na linguagem onírica) e também em suas novas formas de representação do poder. Neste sentido, percebe-se o início de um processo de assimilação da figura profissional do "professor bilingue" que se torna a maior categoria de "homem forte" entre os Awajún, aspecto que é acompanhado pela elaboração de uma nova linguagem visual e imaginativa.

\section{Palavras-chave}

Tesauro: Amazônia, Perú, fronteira, religião.

Autor: índio, memórias. 


\section{Introducción}

En su ensayo sobre la construcción del Estado en contextos periféricos de los Países andinos, Krupa y Nugent afirman la necesidad de repensar las metodologías clásicas de investigación social, proponiendo que las ciencias sociales pongan una mayor atención en las múltiples formas a través de las cuales las poblaciones integran en su vida cotidiana los principios de legitimidad de las normas y los deberes ciudadanos. ${ }^{1}$ Para alcanzar tal propósito, Krupa y Prieto llaman la atención acerca la existencia de una "vida afectiva" del Estado que se presenta como el deseo de sometimiento, esperanza o miedo a través de los cuales las personas se vinculan con la autoridad. ${ }^{2}$

En continuidad con estas tesis, la investigación desarrollada por Cecilia Ortiz nos invita a reflexionar sobre el proceso de "domesticación de los sentimientos" que los misioneros salesianos generaron en el mundo emocional de los indígenas shuar ${ }^{3}$ asentados en su misión a finales del siglo XIX. Tal como la historiadora señala: “[...] la dimensión afectiva en la relación entre el Estado y los individuos ha sido un aspecto aún poco explorado por las ciencias sociales y que merece ser tomado en cuenta en los estudios sobre las formas a través de las cuales las sociedades se identifican con el poder estatal". ${ }^{4}$

A partir de estas consideraciones, nos parece prioritario asumir el afianzamiento del Estado en los territorios fronterizos como el desarrollo de un proceso cultural arraigado a partir de un cambio gradual al interior de la vida cotidiana de los grupos socioculturales ahí presentes. Cambios que se miden en primer lugar dentro de sus esferas emocional, afectiva e imaginativa. En el caso de un contexto de frontera amazónica, podríamos por lo tanto preguntarnos si la presencia del Estado coincide con el momento en el cual los grupos indígenas ahí presentes empiezan a percibirse y auto-representarse como miembros de una sociedad mayor.

Para ello, a lo largo del presente artículo abordaremos la manera en la cual los indígenas awajún ${ }^{5}$ de la región fronteriza del Alto Marañón, en la Amazonía peruana, ${ }^{6}$ fueron progresivamente apropiándose y resemantizando una serie de gestos, actitudes

\footnotetext{
${ }^{1}$ Christopher Krupa y David Nugent (eds), State theory and Andean politics: New approaches to the study of rule (University of Pennsylvania Press, 2015) 5.

${ }^{2}$ Cristopher Krupa y Noguera Prieto, “Corpus Mysticum estatal o ¿cómo podemos pensar el estado en América Latina hoy?”, Iconos 52 (2015): 17.

${ }^{3}$ Grupo jíbaro fuertemente vinculado con los awajún peruanos, y posicionados en el margen ecuatoriano.

${ }^{4}$ Cecilia Ortiz, Shuar, salesianos y militares. La formación del estado en el sur-oriente ecuatoriano 1893 1960. (Quito: FLACSO, 2019) 196.

${ }^{5}$ Grupo indígena considerado dentro de la categoria etno-linguística de los jibaros. Presentes en el territorio peruano, actualmente distribuidos en grupos familiares residentes dentro de cuatro diferentes departamentos (Cajamarca, Amazonas, San Martín y Loreto). En el presente artículo será considerado el caso de los grupos situados en el distrito de Imaza (departamento de Amazonas).

${ }^{6}$ Se trata de una serie de fuentes orales recogidas a lo largo de un trabajo de campo etnográfico en ocasión de mis estudios doctorales. El trabajo etnográfico se ha realizado dentro el distrito de Imaza, provincia de Bagua, región Amazonas entre los años 2012 y 2017.
} 
La visión de la bandera. Memorias oníricas awajún sobre la construcción de una sociedad...

y conocimientos provenientes de la sociedad externa, incorporando estos aprendizajes dentro de sus propios horizontes de imaginación y de percepción. ${ }^{7}$

La reflexión ethnohistórica se enfocará en los procesos de incorporación e reelaboración de las narrativas de "modernidad" y "pertenencia ciudadana" entre los awajún, en consideración de las transformaciones culturales surgidas como consecuencia de los proyectos de "civilización", "conversión", y "nacionalización" operados por diferentes actores, religiosos, militares y civiles, a lo largo del siglo XX.

Entre estos, prestaremos una particular atención a la labor realizada por los miembros del Instituto Lingüístico del Verano (ILV) presentes en la región desde finales de la década de 1940.Un concepto central para el análisis será el de "memorias oníricas". Este refiere a los relatos que los indígenas jibaros elaboran sobre sus supuestas experiencias oníricas anteriores, a las cuales brindan especial importancia como una forma privilegiada de interpretar su presente histórico y para decidir sus acciones futuras. ${ }^{8}$ En ocasión mi investigación doctoral sobre el trabajo sobre las historias de vida de líderes awajún ha permitido evidenciar el rol central, dentro de la narración que las memorias sobre sueños recubren en la reconstrucción de procesos históricos importantes.

En esta lectura sobre el pasado, los narradores suelen reunir la dimensión individual con la colectiva. ${ }^{9}$ Según Anne-Gaël Bilhaut, ${ }^{10}$ dentro de muchas sociedades amazónicas las experiencias oníricas resultan ser instrumentos útiles para comprender la relación que los narradores entretejen con su presente y su pasado, es decir, con el tiempo de la realidad y con el tiempo de la narración. ${ }^{11}$

Por consiguiente, el análisis aquí desarrollado abordará el contenido simbólico presente en las memorias oníricas de las primeras generaciones de profesores bilingües awajún del Alto Marañón, para proponer un modelo de estudio sobre cómo comprender el nivel de incorporación de las enseñanzas promovidas por las misiones en un contexto amazónico de frontera, y evaluar sus consecuencias dentro la formación de una primera comunidad de individuos nacionalizados.

\section{Contexto histórico- geográfico del caso en estudio}

Los awajún del Alto Marañón son un grupo indígena perteneciente al conjunto etno-lingüístico de los jíbaros, situado desde la época colonial en el territorio amazónico

\footnotetext{
${ }^{7}$ David Nugent, "Building the state, making the nation: The bases and limits of state centralization in «modern» Perú", American Anthropologist 96. 2 (1994) : 333-369.

${ }^{8}$ Philippe Descola, Les lances du crépuscule : relations Jivaro, Haute-Amazonie, (París: Plon, 1993) 109.

${ }^{9}$ Silvia Romio, "Suivre le chemin ». : la construction de l>identité politique des Awajún d>Amazonie péruvienne (1920-1980), (Paris : EHESS, 2017).

${ }^{10}$ Anne-Gaël Bilhaut, El sueño de los Záparas: patrimonio onírico de un pueblo de la Alta Amazonía, (Quito: Flacso, 2010) 66.

${ }^{11}$ Cabe mencionar el importante trabajo en tema de memoria onírica y procesos de conversión en sociedades amazónicas realizado por Mina Opas: «Dreaming faith into being: indigenous evangelicals and co-acted experiences of the divine». Temenos-Nordic Journal of Comparative Religion, 52. 2 (2016).
} 
norperuano entre los ríos Marañón, Cenepa, Morona y Santiago. Zona corrispondente a la frontera que actualmente divide el Perú y el Ecuador. Se trata de un área poco explorada hasta tiempos recientes ya sea por su difícil acceso terrestre que por el escaso interés político que generó para ambos países. Es por esta razón que, luego de la supresión de la reducción de Maynas (1767), los combativos grupos indígenas ahí presentes vivieron en un estado de semi-contacto con la sociedad externa hasta la llegada de los misioneros, a mediados del siglo XX. ${ }^{12}$

Posterior a la firma del Protocolo de Río de Janeiro de $1942,{ }^{13}$ los gobiernos de Perú y Ecuador tuvieron la necesidad de definir sus fronteras geopolíticas, una decisión que se tradujo en una serie de proyectos políticos encaminados a construir una "sociedad fronteriza patrióticamente consciente". ${ }^{14}$ En ambos países, el impulso gubernamental para la ocupación territorial por parte de colonos andinos ${ }^{15}$ fue acompañada por una visión estatal de creación de espacios de "civilización" y de "nacionalización" por los grupos indígenas allí asentados ${ }^{16}$.

En el caso del Perú, esto se tradujo en una serie de acuerdos y tratados a mediados de los años 1940, entre los Ministerios de Fomento y de Educación Pública con instituciones religiosas que pudiesen encargarse de esta difícil tarea. ${ }^{17}$ Con este patrocinio, los jesuitas fundan la Prefectura Apostólica de San Francisco del Marañón en Jaén (región Cajamarca), en 1946, a lo cual seguirá la refundación de La Misión de Santa María de Nieva, en 1953, posicionada en el corazón del territorio jíbaro. ${ }^{18}$

Igualmente, importante fue el trabajo realizado por el Instituto Lingüístico de Verano (ILV): desde la firma del convenio con el Estado peruano(1946) sus representantes mostraron un especial interés por instalar una de sus sedes principales en el corazón del Alto Marañón. ${ }^{19}$ A raíz de dichos esfuerzos, en poco más de dos décadas, el ILV consiguió significativos resultados en términos de "educación" y "profesionalización", que contaron con un número considerable de jóvenes awajún dispuestos a recibir y adoptar las nuevas ideas y el estilo de vida que se les venía ofreciendo. ${ }^{20}$

\footnotetext{
${ }^{12}$ Frederica Barclay y Equipo ODECOFROC, Crónica de un Engaño. Los intentos de enajenación del territorio fronterizo awajún en la Cordillera del Cóndor a favor de la Minería, (Lima: Iwgia, 2009) 12.

${ }^{13}$ Protocolo firmado por Perú y Ecuador el año 1941, que da fin al conflicto de fronterizo entre ambos países.

${ }^{14}$ Frederica Barclay, "Pactos entre pueblos indígenas y el Estado en la Amazonía peruana republicana", Amazonía Peruana 32 (2019): 62.

${ }^{15}$ En Perú, la política de migración interna llevada por el primer gobierno del Presidente Fernando Belaunde Terry (1963-1980) se fomentó hacia la construcción de «fronteras vivas» en las regiones amazónicas.

${ }^{16}$ François Bignon, "La militarización de los Orientes peruanos y ecuatorianos (1933-1941)", Amazonía Peruana, XVI. 32 (2019): 138.

${ }^{17}$ Frederica y ODECOFROC 19-20-26.

${ }^{18}$ José Maria Guallart, El vicariato de San Francisco Javier de Marañón: 50 años de una misión jesuita, (Lima : CAAAP, 1997): 42.

${ }^{19}$ Shane Greene, Caminos y carretera. Acostumbrando la indigenidad en la selva peruana, (Lima: IEP, 2009) 161-162.

${ }^{20}$ David Stoll, "The Summer Institute of Linguistics and indigenous movements" Latin American
} 


\section{Presencia de los evangélicos en el Alto Marañón y construcción de un imaginario sobre el "profesor bilingüe"}

Al reconstruir la historia de la evangelización de los awajún del Alto Marañón, vemos que la incursión religiosa, tanto católica como evangélica, se volvió constante y estructurada entre los años ' 50 y ' 70 del siglo XX. ${ }^{21}$ Previamente, hay que anotar el trabajo pionero de la Iglesia del Nazareno, que fundó una misión en el actual distrito de Imaza, dirigida por el pastor Roger Winans, en 1924. ${ }^{22}$ Este hecho tuvo un considerable impacto dentro de diferentes núcleos familiares awajún ubicados en las orillas de los ríos Chiriaco y Marañón. ${ }^{23}$ Desde los años '40, etapa que corresponde a la máxima expansión de la misión, Winans se preocupó en formar a algunos indígenas como colaboradores ${ }^{24}$ sumándole a las enseñanzas propias de una formación pedagógica, conocimientos en temas religiosos. ${ }^{25}$ En 1947, el jesuita Martín Cuesta, ${ }^{26}$ en una de sus habituales visitas a la zona desde la ciudad de Jaen, ${ }^{27}$ escribe en sus diarios -con una cierta sorpresa y preocupación- la larga conversación que sostuvo con uno de los más cercanos colaboradores indígenas de la misión "evangélica", el múun ${ }^{28}$ Daniel Danducho, sobre los temas de conversión religiosa y de interpretación de las Sagradas Escrituras. ${ }^{29}$

Desde los inicios de los años '50, varios jóvenes como Danducho llegaron a ser los primeros intérpretes culturales y traductores de la Biblia dentro de las actividades promovidas por el ILV, además de ser elegidos para tener una formación

\footnotetext{
Perspectives 9. 2 (1982): 92.

${ }^{21}$ Michael Brown, Upriver: the turbulent life and times of an Amazonian people, (Cambridge: Harvard University Press, 2014) 217-218.

${ }^{22}$ Roger Winans, Gospel over the Andes: notes of Roger S. Winans, (Kansas City: Beacon Hill Press, 1955).

${ }^{23}$ Misión fundada y guiada por Roger Winans entre los años 1924 y 1948 en la zona del Alto Marañón. Durante las décadas de 1930 y 1940, Winans y sus sucesores, particularmente el pastor Baltazar Rubio y su esposa, fundaron numerosas misiones en diferentes cuencas del Alto Marañon. Los centros más importantes fueron: Tuntuntsa, Yamayakat y Orakusa (Greene, Shane. Caminos y ...) 147-148.

${ }^{24}$ Informaciones confirmadas por el contenido en las grabaciones realizadas por Daniel Danducho, quien describe su relación personal con Roger Winans desde la infancia hasta la juventud (1948 posiblemente). Grabaciones realizadas por el Instituto Lingüístico de Verano.

${ }^{25}$ Roger Winans 33-37; Silvia Romio 144-147.

${ }^{26}$ José Maria Guallart, El vicariato de San Francisco Javier de Marañón: 50 años de una misión jesuita. (Lima: CAAAP, 1997) 85-98.

${ }^{27}$ Desde el año 1946, el gobierno peruano encomendó a la Compañía de Jesús la región Nord-oeste de la amazonia peruana, con la denominación de Prefectura Apostólica de San Francisco del Marañón, repartida en tres diócesis distintas. Desde 1953. se agregó la parte de la provincia de Jaen, que había quedado dentro de la Diócesis de Cajamarca. Desde 1971 pasa a denominarse como "Prefectura Apostólica de San Francisco Javier", donde, entre sus diferentes tareas, estaba la de realizar la "conversión y civilización" de los grupos jíbaros presentes en los territorios fronterizos, y apoyar el proceso de construcción de una "sociedad nacional".

${ }^{28}$ Múun: figura de autoridad awajún. «un guerrero excepcional, un gran hombre» (Descola, Philippe 174). También: «un hombre grande que constituye la figura central de un grupo de personas, y que es reconocido por su séquito como el personaje principal interlocutor y un verdadero orador (Silvia Romio 17).

${ }^{29}$ José Maria Guallart 98.
} 
como profesor bilingüe. ${ }^{30}$ Luego de un breve periodo de estudio pasado en el centro de formación nacional de Yarinacocha, ${ }^{31}$ estos jóvenes indígenas volvían a la comunidad de origen, donde obtenían un cargo como docente en las escuelas recientemente creadas por los lingüistas. Al interior de dichos espacios su objetivo era de "educar", “convertir" y "nacionalizar" los demás indígenas de la zona. ${ }^{32}$

Como era natural, la actividad pedagógica adoptada por los nóveles maestros awajún era rápidamente acompañada por una marcada ascensión social dentro de la estructura social indígena. ${ }^{33} \mathrm{El}$ ejemplo vivencial que representaban tuvo fuertes repercusiones dentro la expresividad del poder indígena: es decir en las formas de representación del "hombre fuerte" o kakajam. ${ }^{34}$ Diferentes fuentes del tiempo no hablan de cómo estos jóvenes profesores bilingües pasaron en poco tiempo a ocupar diferentes roles de prestigio a la vez, llegando a reunir todos los aspectos del poder que caracterizaban la vida social de las nuevas comunidades, a saber: el trabajo en la escuela, la coordinación de las cooperativas indígenas, las consultas en temas de salud y la dirección en las asambleas comunitarias. ${ }^{35}$ De manera gradual, se va por lo tanto perfilando una inédita figura de autoridad, que llamaremos el "kakajam moderno", quien consolidó su estatus de poder dentro de las comunidades indígenas que iban surgiendo en aquel periodo.

Dentro del discurso de auto-representación elaborado por esta primera generación de profesores bilingües, encontramos una clara intencionalidad de ofrecer respuesta al punto nodal de las reflexiones que ocupaban la atención de la sociedad indígena de aquel tiempo. Nos referimos a las preocupaciones acerca de la transformación social que se estaban viviendo los awajún del Alto Marañón bajo las influencias y los estímulos propuestos por los misioneros. ${ }^{36}$ Entre el modelo de liderazgo del pasado, el kakajam -fundado en el ejercicio del conflicto intertribal, la exhibición de la fuerza y la práctica de la violencia ${ }^{37}$ - y la representación de poder

\footnotetext{
${ }^{30}$ Mildred Larson y Lois Dodds, Treasure in clay pots: An Amazon people on the wheel of change, (Palm Desert: Person to Person Books, 1985) 13.

31 Yarinacocha: lugar cerca de la ciudad de Pucallpa (región Ucayalli). Desde los inicios de los '50, Yarinacocha se volvió el centro principal del trabajo del ILV en la amazonia peruana, para la formación de indígenas literatos y profesionales, de estudios de idiomas indígenas y sobre todo de traducción de la Biblia.

32 El tema de la preparación de jóvenes para promover la obra misionera al interior de sus propios "comuneros", hecho que impulsa un proceso de renovación dentro de las formas de liderazgo tradicional, fue desarrollado tempranamente por los adventistas del Séptimo Días, desde la década de 1920, entre los Asháninca del Perené. Anteriormente, los adventistas venían haciéndolo en el altiplano peruano, con la población aymara, desde la década de 1910 (La Serna, Juan Carlos. "Viviendo con el diablo en casa. La enfermedad, hechicería infantil y violencia entre los ashánincas desde la perspectiva misionera adventista”. Véase Bulletin de l'Institut français d'études andines, 40.1 (2011): 82-83.

${ }^{33}$ Shane Greene 139-180.

${ }^{34}$ Kakajam: «valiente, hábil táctico, impaciente ante la muerte, virtuoso en el dominio retórico del diálogo formal, generoso en la hospitalidad, obstinado en la venganza» Philippe Descola, "Les lances du” 174.

35 David Stoll, "The Summer Institute of Linguistics and indigenous movements", Latin American Perspectives 9. 2 (1982): 91.

${ }^{36}$ Mildred Larson y Lois Dodds 105-115-116.

${ }^{37}$ Anne Christine Taylor, "Devenir jivaro. Le statut de 1'homicide guerrier en Amazonie“, Cahiers
} 
del "hombre moderno" impulsado por los misioneros, como letrado, "pacifista" y profesional, la sociedad awajún de los años 1950-1960 estaba trazando los perímetros de sus nuevas figuras de referencia. ${ }^{38}$

Como primer paso en este periodo de cambio sociocultural, el profesor bilingüe vino a desempeñar un rol fundamental tanto en el proceso hacia una "pacificación social indígena" 39 como en la fundación de una "sociedad nueva" entendida como una forma de nacionalización de la frontera. Estos resultados fueron posibles gracias a la sorprendente acogida que la nueva figura del profesor bilingüe encontró entre los awajún, quienes la asumieron como una forma de transformación de su antigua figura de autoridad, y pasaron a interpretarla como la representación de un "kakajam moderno".

Con este término queremos indicar la figura del nuevo "guerrero awajún" que lucha contra los mestizos instalados en la zona (los comerciantes, los patrones, los agricultores andinos), con los conocimientos adquiridos en las escuelas. Esta figura de liderazgo despertó un extraordinario interés entre los awajún, reconocible en la cuantidad de indígenas que pidieron acceder a los nuevos centros educativos bilingüe esparcidos en toda la región, o de conseguir el acceso para sus hijos. ${ }^{40}$

Para entender la respuesta favorable que los awajún tuvieron antes la propuesta "civilizatoria" del ILV, es igualmente importante considerar el tipo de relación afectiva que se estableció entre los jóvenes indígenas letrados y los lingüistas norteamericanos. Estos últimos muy rápidamente se convirtieron en una figura de autoridad ejemplar a sus ojos, posicionándose a medio camino entre el guía espiritual, el "padre" y el buen patrón. ${ }^{41}$ A su vez, cabe tener en cuenta las implicancias generadas por el connubio entre las prácticas tradicionales awajún relacionadas a la formación de la nueva figura de poder (el "kakajam moderno"), con la reapropiación de una serie de costumbres y mensajes propios de los predicadores evangélicos. ${ }^{42}$

La figura del misionero, con sus saberes, su poder económico -proveniente de las actividades comerciales desempeñadas en la misión- y su capacidad de adaptación en espacios geográficos y culturales distintos, se convirtió rápidamente en un modelo

\footnotetext{
d'anthropologie sociale 2 (2006): 67.

${ }^{38}$ Silvia Romio, "Los awajún contra Herzog. Uso del conflicto en la construcción del liderazgo indígena", Política y poder en la Amazonía. Estrategias de los pueblos indigenas en los nuevos escenarios de los países andinos, Surrallés, A., Correa, F., Espinosa, O. (eds.). (Bogotá: Universidad Nacional de Colombia, 2016).

${ }^{39}$ Con «pacificación social indígena» estamos indicando el debilitamiento de las dinámicas de guerras intertribales. En cambio, la dimensión del conflicto intra-tribal en de las comunidades nativas, se incrementó a lo largo del tiempo bajo la forma de la brujería.

40 José Maria Guallart, “El vicariato de” 135.

${ }^{41}$ Silvia Romio, «Suivre le chemin».: la construction de lidentité politique des Awajún d>Amazonie péruvienne (1920-1980). (Phd Dissertation, Paris: Ecole des Hautes Etudes en Sciences Sociales, 2017).

${ }^{42}$ Silvia Romio, "La voz de Dios y la respuesta awajún. El caso de la Iglesia Bíblica Awajún en el Alto Marañón (Amazonía Peruana)”, Buletin del Ifea 47.3 (2018): 250.
} 
de autoridad y prestigio fuertemente atractivo entre los indígenas de la zona. Tanto así que los mismos discípulos comenzaron a copiar su gestualidad y expresiones de los misioneros para re-adaptarlas a sus necesidades. Con esta finalidad, los primeros indígenas formados en la misión terminaron reelaborando las ideas y los conceptos que el mensaje misionero buscaba transmitir, iniciando la formación de una nueva perspectiva de liderazgo y de una diferente sensibilidad indígena. ${ }^{43}$

\section{Las memorias de Danducho. La llegada de la "modernidad" a una comunidad awajún}

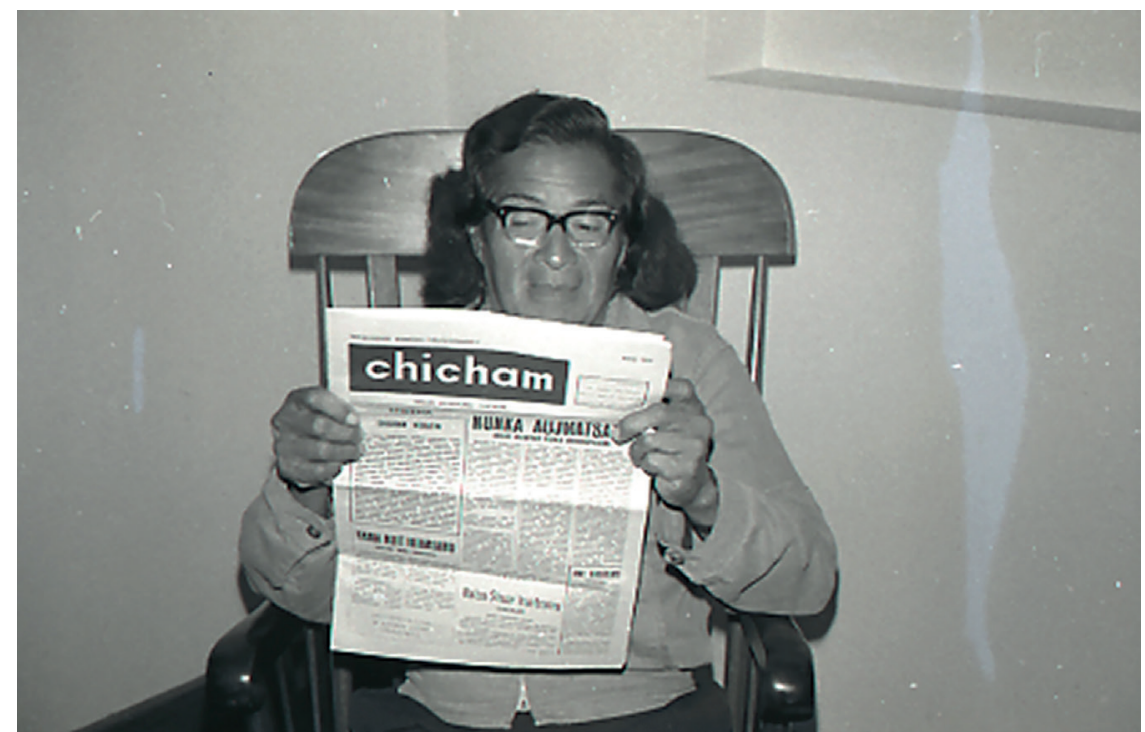

Imagen 1. El múun Daniel Danducho leyendo un periódico en lengua awajún. Fuente: Foto tomada por Mildred Larson en los años 1960. Archivo personal de la familia Danducho.

Que el múun Daniel Danducho haya sido "el primero en introducir la educación bilingüe entre los awajún" corresponde a una afirmación fuertemente compartida tanto por la sociedad indígena del Alto Marañón, como por numerosas fuentes escritas de la época. ${ }^{44}$ Como afirma Shane Greene, ${ }^{45}$ los lingüistas del ILV vieron en esta persona, que había recibido una primera formación religiosa por parte del pastor nazareno Roger Winans (Iglesia del Nazareno) en su niñez, ${ }^{46}$ la figura idónea para dar cuerpo al proyecto de construcción de un "buen salvaje convertido"

\footnotetext{
${ }^{43}$ Silvia Romio 251.

44 José Maria Guallart 145.

${ }^{45}$ Shane Greene 148.

${ }^{46}$ Después de su primera etapa de formación en la misión de la Iglesia Evangélica del Nazareno a inicios de los años 1940, Daniel Danducho, por mediación de los lingüistas presentes en la misión de Imaza, empieza sus viajes en el 1953 a Yarinacocha (región de Pucallpa, sede central del ILV). El tipo de formación académica, religiosa y personal que ahí recibió, representó un evento excepcional para su comunidad. El prestigio adquirido le permitirá asumir, una vez de regreso al Alto Marañón, la autoridad necesaria para encarnar el modelo de «hombre fuerte moderno» e «indígena nacionalizado» ante sus coterráneos. Shane Greene164.
} 
y de "profesional indígena". ${ }^{47}$ Dotado de una personalidad carismática y brillante, Danducho terminó por personificar el modelo del "kakajam moderno". Es decir, del indígena letrado capaz de reinterpretar los mensajes evangélicos y los aprendizajes escolares para elaborar un inédito modelo de autoridad indígena.

Para entender en profundidad este proceso, nos resulta imprescindible considerar la capacidad mostrada por Danducho en la comprensión de los mensajes bíblicos y su reelaboración dentro de un lenguaje político original. Este análisis es hoy en día posible gracias a la tenencia de un material único: el archivo completo de sus memorias orales grabadas por el ILV en los años ' $70 .{ }^{48} \mathrm{El}$ descubrimiento de dicho material nos ha permitido acceder a una fuente excepcional para acercarse a la perspectiva íntima de esta figura histórica, facilitando una reflexión más amplia sobre las formas de reinterpretación que los primeros profesores awajún estuvieron realizando de los mensajes transmitidos por los lingüistas.

Entre los diferentes relatos ahí presentes, dos fragmentos muestran ser los más significativos para entender algunos conceptos clave sobre el ideal de "kakajam moderno" expresado por Danducho. Primeramente, consideraremos el relato en el que recuerda cómo convenció a los jóvenes de su comunidad de origen para participar en la construcción de la primera escuela bilingüe awajún. En segundo lugar, en el siguiente apartado, proponemos el extracto de una reflexión de Danducho sobre el rol que el "indígena letrado" tiene que asumir dentro de las "nuevas sociedades" indígenas que se estaban fundando en la región.

Bueno, yo estando en Yarinacocha, le rogaba a Shilas Kuñachi ${ }^{49}$ y los demás otros para que él, con los padres de familia, que haga una casa escolar y no ha hecho nada, entonces yo llegué a [inaudible 21:52] con los niños, entonces a hablar a los padres de familia, porque no tenían interés y como no lo conocían la escuela, entonces yo hablé con los niños. Entonces yo dije: bueno, joigan niños! Ahora, el gobierno, el Instituto nos quiere que aprendamos, él nos va a ayudar todo lo posible, [...] entonces los niños dijeron: ¡qué bueno! Muy bien, entonces tuvieron interés, dijeron: bueno si los padres de familia no quisieran, y no quieren trabajar, entonces trabajamos nosotros, como quiera usted y cuando ya seremos grandes haremos mejores casas. (Daniel Danducho, grabación. 9, $\min .21: 43)$

\footnotetext{
${ }^{47}$ Se trataría de un equivalente del líder indígena Tariri entre los Candoshi, es decir, la figura del joven y sangriento líder guerrero que, un día decidió convertirse a la fe evangélica y seguir las enseñanzas de los lingüistas. Surrallés 275. Al igual que Tariri, la vida de Daniel Danducho se convirtió, a través de la propaganda del ILV, en un ejemplo de fuerza del maestro bilingüe y líder político entre todos los awajún de la zona. Tariri Wallis, My Story: From Jungle Killer to Christian Missionary (Hodder and Stoughton, 1966).

${ }^{48}$ Se trata de un conjunto de grabaciones realizadas por el propio Daniel Danducho en colaboración con la lingüista Mildred Larson como material de apoyo a la redacción del texto «Treasure in clay pots» El descubrimiento de este material, de publicación futura, ha sido posible gracias a la colaboración de Otoniel Danducho, hijo de Daniel Danducho.

${ }^{49}$ Figura de autoridad entre los awajún del actual distrito de Imaza, al tiempo múun y formado por la misión de la Iglesia del Nazareno. Sucesivamente, siguiendo el ejemplo de Danducho, Shilas Kuñachi también recibirá una formación en Yarinacocha llegando a ser un profesor bilingüe awajún altamente prestigioso.
} 
Según este primer relato, al momento de la puesta en marcha del primer centro de formación bilingüe en el Alto Marañón, Daniel Danducho encontró la oposición de muchos jefes de familia (múun) que veían con recelo la posibilidad que un awajún mismo pudiera enseñar la lengua de los "blancos". A pesar de ello, la primera etapa del proyecto resultó ser muy exitosa, gracias a la confianza que Danducho supo inspirar entre los "niños" del grupo, quienes aceptaron participar no obstante la renuencia de los "ancianos". En la reconstrucción del pasado, Danducho privilegia el uso de elementos innovadores en el lenguaje tanto verbal como visual, decisiones que manifiestan los signos de cambio en la sensibilidad awajún que él está empezando a elaborar y proponer entre los suyos.

Observando el contenido mismo de la narración, vemos que se evidencia un cisma entre la percepción del tiempo, es decir entre la dimensión del pasado y la del presente. Siguiendo el sentido del relato, la posibilidad de adquirir una educación escolar se volvía accesible a partir de una toma de decisión explicita de los jóvenes, posición que significaba el ir en contra de la opinión de las autoridades locales o "ancianos" (los múun). Esta actitud implicaba una ruptura con las normas de comportamiento habituales entre los awajún, según las cuales la voluntad del múun correspondía a una decisión consensuada por todos los demás miembros del grupo. ${ }^{50}$ Empieza por lo tanto a hacerse visible la importancia de la "toma de decisión" de los adeptos de la "nueva sociedad letrada", aspecto que nos recuerda la aptitud propuesta por las iglesias evangélicas como primer paso hacia la consolidación de una nueva comunidad religiosa. Que, a su vez, correspondería al acceso a una nueva dimensión temporal dentro de la trayectoria individual del creyente: la "modernidad". ${ }^{51}$

Paralelamente, se observa en el discurso la integración de una serie de conceptos e imágenes propios de la perspectiva cultural occidental y muy presentes en el lenguaje evangélico. Encontramos el uso del término "niños" utilizado por Danducho para referirse a las personas que aún no consolidan su estatus de autoridad en la comunidad, es decir, aquellos que todavía no han realizado el ritual de iniciación hacia la adultez (jinta ainbau). ${ }^{52}$ En una sociedad pre-escolar, como es el caso de los awajún antes de la llegada de los misioneros, cada individuo construía su estatus de autoridad como individuo a través de un esfuerzo gradual por acumular experiencia y conocimientos. ${ }^{53}$ En este sentido, la distinción entre la condición de "adolescente" y la de "niño" propia de la sociedad occidental, estaba ausente entre los awajún, dado que esta distinción dependía de la realización de dicho ritual (jinta ainbau).

\footnotetext{
${ }^{50}$ Henning Siverts, (1972); Micheal Brown 27.

${ }^{51}$ Joel Robbins y otros, "Continuity thinkin" 5; Joel Robbins, "Evangelical conversion” 560.

52 Jinta Ainbau: Con ese término los awajún suelen referirse a un ritual de iniciación bastante consolidado entre todos los grupos jíbaros, en el que un individuo se aleja de la sociedad y se queda en un lugar solitario donde, gracias a una dieta especial y a la toma de plantas alucinógenas, logrará adquirir un estado de conciencia particular que le facilitará el contacto con un ser extrahumano, el ajutap. Según los relatos recogidos, ese espíritu se manifiesta a través de una voz altisonante y, bajo forma de mando, trasmite al adepto indicaciones precisas para sus decisiones futuras.

${ }^{53}$ Elke Mader 420.
} 
En el relato aquí considerado, la palabra "niños" y su centralidad en la historia expresan una nueva visión de la realidad. En primer lugar, el término "niños" se refiere a todos los jóvenes que se encontraban en el inicio de su formación escolar, independientemente de su edad. En segundo lugar, hay que recordar la importancia que reviste la construcción de una vivienda propia (maloka $)^{54}$ dentro de la percepción del mundo jíbaro, en cuanto punto de partida como lugar de socialización y de representación de "persona adulta" ante su comunidad. ${ }^{55}$ Vemos, por lo tanto, que la imagen de la construcción de una escuela por parte de los "niños" equivale a la representación simbólica del asentamiento de las bases de una nueva forma de sociabilidad, así como el surgimiento de un nuevo imaginario en la trayectoria personal que cada awajún deberá cumplir para convertirse en "persona adulta" dentro del tiempo de cambio que les tocó vivir con la llegada de los misioneros y su incorporación a una hipotética sociedad nacional.

Cuando Daniel Danducho describe a sus alumnos como "niños", nos ofrece una clave fundamental para entender otro proceso de cambio que él está proponiendo: la reapropiación y adaptación de un lenguaje cristiano para describir su propia experiencia de liderazgo. En efecto, hay aquí una interesante yuxtaposición entre la imagen de Danducho y la de Jesús Nazareno. Esto se realiza gracias a la utilización del célebre extracto del Nuevo Testamento que describe el interés de Jesús por dirigirse a los niños: "porque de ellos es el reino de los cielos". ${ }^{56}$

En ambos casos, en la historia oral de Daniel Danducho y en el pasaje bíblico, los "niños" ocupan un lugar central, identificados como seres puros capaces de aceptar, sin prejuicios, la "buena nueva" del mensaje cristiano. En este caso, esto significaría la propuesta del educador awajún que identifica el punto de origen de la "nueva sociedad" en la reunión de los awajún escolarizados y nacionalizados. Los objetivos de la narrativa de Daniel Danducho son evidentes. Primero, afirmar la autoridad del narrador como portador de una novedad absoluta para la sociedad awajún, tanto en la noción de "kakajam moderno" como en las nuevas formas de "sociabilidad". Segundo, subrayar que el acceso a este cambio solo será posible rompiendo con las normas tradicionalmente establecidas. Estos elementos, como sabemos, tenían una directa correspondencia con los ejes principales del mensaje cristiano. Estas últimas, dentro de su visión milenarista, buscaban (y buscan) orientar a sus adeptos hacia una ruptura con la tradición cultural local a partir de la "conversión" a la iglesia evangélica. ${ }^{57}$

Este proceso de transformación iría de la mano con el proyecto de construcción de "nuevas comunidades", igualmente promotoras de un sentido de pertenencia nacional. En otras palabras, tal como lo veremos en la próxima sección, ser miembro de esta nueva comunidad implicaba la transformación en un "individuo moderno" y en

\footnotetext{
${ }^{54}$ «Maloka»: término genérico utilizado para describir casas hechas de cañas y hachas de madera, construidas de manera tradicional.

${ }^{55}$ Alexandre Surrallés, 132.

${ }^{56}$ Paso biblico Mt 5: 3-11.

${ }^{57}$ Joel Robbins 7.
} 
un "ciudadano nacional". Para alcanzar este objetivo y la difusión de los imaginarios conexos, los lingüistas y los profesores bilingües como Danducho hicieron un amplio uso de una serie de objetos simbólicos como la bandera y el himno nacional, elementos hasta ese momento absolutamente desconocidos dentro de la realidad indígena.

\section{La memoria sobre la fundación de las nuevas escuelas como núcleos de "nuevas sociedades" de frontera}

Vamos ahora a considerar un punto sucesivo dentro de las memorias orales de Danducho:

[...] desde el año 1956 había más líos, los mestizos con los aguarunas, y con los aguarunas entre comunidades. Entonces, para poder resolver estos problemas que habían y pero... por fin habiendo las escuelas, en las comunidades, entonces pudimos tratar de resolver todos esos problemas que se presentaba con los mestizos y con entre los aguarunas. Entonces, yo les dije todos líos que ha habido antes, mejor que desaparezcan y no acordemos más porque ahora estamos formando otra nueva sociedad." (Daniel Danducho, grabación 10, min.27:01)

Este punto nos parece particularmente significativo para la reflexión que estamos desarrollando, siendo que pone en luz dos asuntos clave dentro del proceso de transformación representado por Danducho. Es decir la transformación de "hombre fuerte" a "kakajam moderno". Por un lado, él desaconseja abiertamente el uso de la violencia, entendida como la herramienta anteriormente utilizada para resolver todo tipo de conflicto social. El nuevo modelo de liderazgo indígena, el "kakajam moderno", tiene que considerar su rol como el de un "intermediario cultural" y de un partidario de su propia autonomía económica, todo ello dentro de un clima social no violento.

Los proyectos de profesionalización, las empresas comerciales indígenas y los aprendizajes sobre los sistemas de justicia occidental son propuestos como las únicas soluciones posibles para la realización de una sociedad constituida por “indígenas modernos". En segundo lugar, Danducho habla abiertamente de los nuevos centros, es decir, las comunidades nacidas alrededor de las escuelas como de "otras sociedades". Con estas palabras, el narrador asume y reelabora la visión propuesta por los evangélicos, es decir, de ser el fundador de una dimensión espaciotemporal innovadora, constituida por individuos que han decidido asumir un estilo de vida nuevo, respondiendo a las aspiraciones de ser "civilizados", "convertidos" y "nacionalizados".-

La reunión de los dos relatos permite tener una idea más clara sobre el tipo de representación narrativa que Danducho va proponiendo del "kakajam moderno" y de la "nueva sociedad" indígena. Conceptos reconocibles tanto en el uso de las imágenes simbólicas que en los cambios adoptados dentro de la estructura misma del relato. En los dos casos citados, el narrador adapta el metarelato cristiano a sus necesidades de confirmación de su nuevo estatus de autoridad y lo hace realizando un proceso de sincretismo entre estructuras de la narración nuevas con otras propias de la tradición oral awajún. 
Observamos, por lo tanto, que en lugar del tiempo mítico o de la dimensión onírica normalmente utilizados en la narrativa awajún para transmitir memorias de eventos importantes, la narración de Danducho se desarrolla dentro de un tiempo netamente histórico y lineal. En segunda instancia, vemos que el narrador -actor único del relato mismo- se retrae como un héroe solitario, encargado de realizar la acción transformadora. Esta perspectiva de la narración se posicionaría como un elemento en neta continuidad con el género autobiográfico históricamente desarrollado dentro de la tradición oral de los grupos jíbaros. ${ }^{58}$

Si de un lado la historia propone un cambio importante frente al registro narrativo autobiográfico usual (es decir, la pérdida de la dimensión onírica); del otro, eso termina por reafirmar la continuidad de una reconstrucción histórica a partir de la vida ejemplar de un individuo excepcional. Según esta última, vemos que el héroe indígena se impone siempre como el "actor único y motor creador" del cambio, dentro de una perspectiva donde desaparece por completo toda referencia a una dimensión colectiva del proceso histórico, de la misma manera que están ausentes los actores no indígenas. ${ }^{59}$

El elemento inédito que caracteriza esta narración corresponde a la capacidad de síntesis que el narrador realiza para fusionar elementos centrales del mensaje cristiano con la dimensión heroica del sujeto awajún tradicional. Hablamos, por lo tanto, de un protagonista-narrador awajún que busca construir un nuevo modelo de "kakajam" a través su auto-representación como un nuevo "Jesús" o como un "predicador", donde su accionar exhorta a "la transformación moral" en los "niños", es decir sus futuros aprendices.

\section{De la Biblia a la bandera. Memorias oníricas de la segunda generación de profesores bilingües}

El análisis de los relatos autobiográficos de diferentes maestros awajún bilingües de la generación siguiente, ${ }^{60}$ nos permite reconocer el impacto que los ejemplos de Danducho como "kakajam moderno" y como "indígena pacifista y civilizado" tuvo dentro de la sociedad de su tiempo. A través de la exposición de la imagen de Danducho tal como sigue siendo transmitida, podremos valorar su influencia en la forma de autorepresentación de dicho grupo de educadores. Aquí incluimos la versión propuesta por el múun y profesor bilingüe César Inoach, ${ }^{61}$ muy similar a la recordada por otros coetáneos:

\footnotetext{
$\overline{58}$ Taylor (1993); Taylor (2007); Rubenstein (2012).

${ }^{59}$ Taylor «Sick of History: Contrasting Regimes of Historicity in the Upper Amazon», Time and Memory in Indigenous Amazonia. Anthropological Perspectives, Fausto, C. et Heckenberger, M. (ed.s)., (Florida: University Press of Florida, 2007) 147.

${ }^{60}$ Este análisis se basa en testimonios recogidos a diferentes miembros de los grupos Paati y Paz. Los principales interlocutores son: Fermin Tiwi Paati, David Kuñachil, César Inoach, Hugo Shajían, Clementina Paati, Alberto Tiwi, David Kuñachil, Elsa Kaikat, Isaac Paz y Luciana Dekentai. La mayoría de las personas entrevistadas estuvieron entre los primeros alumnos de Danducho o frecuentaron las escuelas fundadas por él.

${ }^{61}$ César Inoach proviene de la comunidad de Yamayakat, donde pudo estudiar en la sede local del ILV y luego trabajar como profesor bilingüe. Durante su juventud, conoció personalmente a Daniel Danducho, quien fue su compañero en la escuela de Yamayakat, dirigida primero por la Iglesia Nazarena y luego por el ILV entre los años 1940 y 1970.
} 
En el 1953, cuando estaba estudiando como profesor, Daniel Danducho tuvo una visión. Una noche contó. En el sueño, él había presentado la bandera. Él subiendo un cerro, con la asta de la bandera a la mano. Y atrás, todo lleno de estrellas nacidas. Por eso él fue llamado doctor de las letras y de la educación bilingüe". (Cesar Inoach, comunidad de Yamayakat, 03-06-2014)

El relato onírico evocado por César Inoach da cuenta de un individuo que sube a una montaña con una bandera en la mano como única arma. Esto denota un importante elemento de divergencia con la tradición de las memorias oníricas de los kakajam anteriores, que constituían un imaginario de confrontación y de gloriosa victoria en contra de un hipotético enemigo. ${ }^{62} \mathrm{La}$ desaparición de toda referencia a cualquier elemento de lucha corresponde a la respuesta positiva frente a la influencia de los primeros misioneros, quienes exhortaban al abandono de la violencia intertribal como primer paso hacia la "conversión" y la "transformación interior" ${ }^{63}$

Un discurso, como ya hemos visto, profundamente apoyado por la primera generación de profesores bilingües, como fue el caso del múun Danducho. En ese sentido, vemos aquí que dicho proceso de transformación cultural inicia con un cambio en el lenguaje narrativo, donde la dimensión guerrera viene a ser sustituida por una imagen más sosegada: la ascensión a la montaña. La perspectiva del éxito personal se proyecta a través del cumplimento de un desafío personal consigo mismo, en lugar de la eliminación física de un Otro, el enemigo. Una vez en la cima de la montaña, el protagonista se encuentra con una cascada de estrellas "recién nacidas", elemento narrativo que representaría a los centros escolares fundados por Danducho y sus primeros alumnos. ${ }^{64}$

La relación pacífica y armoniosa que el sujeto protagonista de la memoria onírica (Danducho) asume con su entorno (la cascada de "estrellas recién nacidas") termina por brindar una representación visual de la función conciliadora que esta figura de autoridad busca asumir. En lugar de las sensaciones de miedo, rencor y venganza que los relatos oníricos tradicionalmente relacionados con las figuras de kakajam tenían que inspirar, ${ }^{65}$ estos nuevos constructos narrativos elaboran una diferente forma de representación de la dimensión de autoridad indígena.

Despojado de todo elemento histórico, el relato deviene aquí en una auténtica narración onírica, vehículo de diferentes interpretaciones simultáneas, que será a la vez paradigma de referencia para las auto-representaciones de los profesores awajún de la siguiente generación. Como segundo ejemplo, citamos ahora un extracto del relato autobiográfico propuesto por el profesor bilingüe David Kuñachi, quien presenta una interesante reapropiación de muchos de los elementos narrativos propios de la memoria onírica de Danducho. ${ }^{66}$

\footnotetext{
${ }^{62}$ Taylor (1993); Taylor (2007).

${ }^{63}$ Priest, Robert 148.

${ }^{64}$ Explicación brindada por el narrador mismo.

${ }^{65}$ Steve Rubenstein, "Importance of vision among the Amazonian Shuar", Chicago Journal, Current Anthropology, 53.1 (2012): 46; Taylor, Anne Chistine 433-434.

${ }^{66}$ David Kuñachi fue familiar de Daniel Danducho y profesor bilingue awajún de la comunidad de Nazareth
} 
La visión de la bandera. Memorias oníricas awajún sobre la construcción de una sociedad...

Cuando yo estaba asistiendo al primer curso de educación bilingüe en Nazareth, tuve una visión. Por lado derecho había tremendo cerro, cerro Lápiz. Yo soñé que había subido a la punta de ese cerro y había visto golondrinas, cantidad de golondrinas, por los bosques, en los ríos, en las quebradas. De repente porque cuando adquirí el trabajo de profesor... cuando llegué a ser director de una primera escuela de Nazareth, los alumnos... yo matriculé alumnos de diferentes comunidades" (David Kuñachi, comunidad de Nazareth, 04-05-2014).

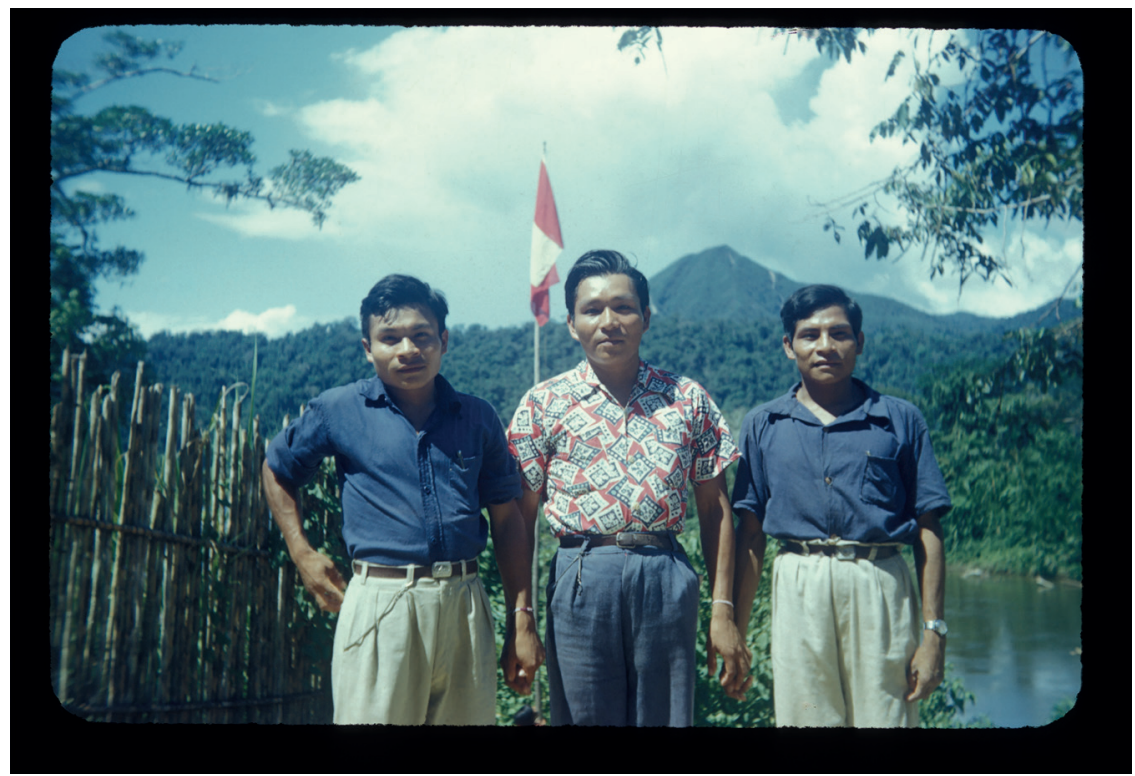

Imagen 2. Tres jóvenes awajún profesores bilingües. En la izquierda, David Kuñachil. Foto tomada en la comunidad de Nazareth, en las espaldas es visible el cerro que es presente en muchas memorias oníricas.

Fuente: Foto tomada por Mildred Larson en los años 70. Publicada en el libro "Treasure in clay pots" (1985). Archivo personal de la familia Danducho.

\section{Soñar con las mariposas. El rol "pacifista" y "patriótico" de los profesores bilingües}

En las memorias oníricas hasta aquí consideradas, el corpus imaginativo predominante muestra ser fuertemente influenciado por los mensajes propios de la doctrina evangélica, la cual buscaba proponer una visión de "cambio social" y "transformación cultural” entre los awajún a través de la figura del profesional indígena. Estos últimos, poco a poco, pasaron a reelaborar estos mensajes construyendo formas de expresividad propias para externar el poder político de los "kakajam modernos".

De forma implícita, los nuevos sujetos de autoridad terminaban por resaltar la capacidad individual al "optar por una decisión de cambio". En todos los casos

particularmente respetado. Desde los años '60, David substituyó Daniel Danducho en el cargo de director de la escuela bilingue presente en Nazareth. Según los escritos de Mildred Larson, David Kuñachi fue una de las figuras más representativa de la segunda generación de profesionales formados por el ILV en los años' 60 - '70. 
citados, podemos señalar que el "cambio" para los profesores bilingües awajún pasaba por la posibilidad (todavía imaginaria en ese entonces) de una futura inclusión dentro de la sociedad nacional mayor. Y esto, en su imaginario, hubiera sido posible a través de la modificación del sentido de los conceptos de "poder" y de "representación de la autoridad", pero también a través de una toma de decisión individual y racional de cada individuo hacia una transformación de su "mundo interior".

A través de las memorias oníricas aquí reportadas, observamos que la voluntad de formarse como "kakajam moderno", en lugar de "guerrero kakajam", está representada visualmente a través de la imagen de un individuo heroico y solitario, posicionado dentro de una naturaleza armoniosa, que no exterioriza actitud violenta alguna, ni es acompañado de sentimientos de odio, venganza u hostilidad, tal como sucedía en el pasado. ${ }^{67}$

En ese sentido, para comprender el significado de la modificación aportada por las imágenes oníricas que caracterizan estos nuevos agentes de poder, se debe tener en consideración las diferentes emociones que acompañaban estos relatos y que los narradores deseaban suscitar en sus adeptos al momento de verbalizar sus recuerdos. Estamos hablando de las sensaciones de armonía y satisfacción que emergían de la representación heroica de estas nuevas figuras de poder, solitarias y pacíficas.

De esta forma, el cambio en la percepción de la realidad propuesto por esas nuevas figuras de autoridad indígena que anhelan ser integradas como miembros de una "sociedad civilizada mayor", no se limita solo al rechazo de un accionar violento. Dentro de sus relatos oníricos, es importante remarcar la introducción de un lenguaje visual innovador, que les permite elaborar una autorepresentación caracterizada por nuevos parámetros figurativos e emocionales. Efectivamente, para el grupo de profesionales indígenas de la segunda generación, el referente principal resulta ser el conjunto imaginativo propio del lenguaje patriótico nacional, elemento que da forma a la representación de su anhelo de ser reconocidos como legítimos miembros, en cuanto profesionales, de la sociedad nacional.

En tal sentido, en el relato propuesto por César Inoach, la imagen de Daniel Danducho que llega a la cima de la montaña con la bandera en la mano, nos permite identificarlo con la representación alegórica de la Marianne que enarbola la bandera francesa, símbolo por excelencia del republicanismo francés. Además de ser un elemento simbólico históricamente asumido (y transformado) por la imaginación patriótica americana. Sin embargo, como sabemos, estos dos elementos simbólicos -la Marianne y la bandera nacional- son referencias culturales de primer orden en la iconografía republicana del Perú, así como en la formación personal de los misioneros y lingüistas norteamericanos del ILV.

En otras palabras, la narración onírica reflejaría la influencia de una cierta imaginación patriótica que los misioneros habrían transmitido a los primeros

${ }^{67}$ Anne Christine Taylor 433-434. 
profesores bilingües en su formación. Este atributo se transformaría en una herramienta empleada por los mismos narradores para sus nuevas auto-representaciones, como "hombres fuertes modernos" y "autores de un nuevo modelo de sociabilidad". Es decir, donde la expresión del poder no pasaba por la exteriorización de la fuerza. Esta maniobra discursiva evidencia la capacidad que tienen los awajún para mantener, en sus expresiones narrativas (y su consecuente percepción de la realidad histórica), una cierta flexibilidad y permeabilidad en los límites que separan su bagaje imaginario tradicional de las influencias externas.

\section{Conclusiones}

El análisis de las memorias oníricas de los primeros actores indígenas portadores de este cambio nos ha permitido conocer las formas más íntimas de estos cambios, es decir, cómo los mensajes propuestos por los religiosos terminaron por modificar el mundo sensible de los indígenas awajún convertidos y profesionalizados. La renovación del imaginario indígena terminó por reunir la figura del "profesor bilingüe" con el prestigio y la autoridad propios de un "hombre fuerte" moderno (kakajam). Esto fue posible a partir de la elaboración de un lenguaje visual y de imaginarios diferentes, resultados de la fusión entre expectativas e imágenes locales con aquellas recientemente incorporadas por los intercambios con el mundo externo.

El trabajo de reunión, análisis y contraposición de diferentes fuentes orales indígenas nos ha permitido comprender la transformación que este nuevo lenguaje simbólico ha tenido en el marco de los primeros diez años de labor misional entre los awajún. En los relatos de Danducho, que corresponden a un buen ejemplo del imaginario manejado por la primera generación de profesores bilingües awajún, la atención del narrador se focalizaba en encontrar una fusión entre la figura del poder indígena (kakajam) con la figura del predicador evangélico y los mensajes conexos a estas dos realidades. En cambio, en la generación sucesiva, hemos encontrado una mayor predisposición para el uso de un lenguaje visual fuertemente vinculado con la simbología nacional. Además de la continuidad con el modelo de liderazgo representando por Danducho, es decir, el modelo del "pacificador" y del "indígena patriótico".

En conclusión, podríamos afirmar que, en su rol de primeros profesionales indígenas, los awajún literatos se impusieron dentro de las nacientes comunidades indígenas como los promotores principales de una nueva visión del "individuo adulto" y del "hombre fuerte moderno" ("kakajam"). Modelos e ideales que se expresaron a través de un lenguaje visual nuevo, reconocible a través las memorias oníricas actualmente transmitidas. Además, estos líderes promovieron una forma diferente de ver y percibir sus relaciones con el mundo exterior. Gracias a estos nuevos imaginarios de referencia, ellos llegaron a consolidar su papel como "agentes pacificadores" y "profesionales".

En este sentido, impulsaron el desarrollo de un primer imaginario alrededor del prestigio de ser "indígenas modernos" y "patrióticos". Estos resultados fueron 
fundamentales dentro los esfuerzos de las misiones en construir una primera sociedad de frontera en el Alto Marañón, formada por comunidades indígenas emocionalmente predispuestas en aceptar su futura inclusión en la sociedad nacional. Como describe Stoll, ${ }^{68}$ parte del trabajo desarrollado por los lingüistas de aquel tiempo fue transmitir a los indígenas, a través de la figura del "profesor bilingüe", sentimientos de "aceptación" y de "expectativas entusiastas" sobre los cambios culturales que se esperaban que ellos incorporen, debido a las futuras interrelaciones con los colonos. ${ }^{69}$ De la misma forma, los lingüistas lograron llevar entre los indígenas la percepción de ser "parte integrante" de un Estado nacional mayor en tanto autores de su propio "proceso de modernización" y no como sus enemigos históricos.

\section{Bibliografia}

\section{Fuentes Secundarias}

\section{Libros}

Bilhaut, Anne-Gaël. El sueño de los Záparas: patrimonio onírico de un pueblo de la Alta Amazonía. Quito: Flacso-Sede Ecuador, 2010.

Brown, Micheal. Una paz incierta. Lima: CAAAP, 1984.

Brown, Micheal. Upriver: the turbulent life and times of an Amazonian people. Cambridge, Harvard University Press, 2014.

Descola, Philippe. Les lances du crépuscule: relations Jivaro, Haute-Amazonie. París: Plon, 1993.

Fausto, C. et Heckenberger, M. (ed.s). Time and Memory in Indigenous Amazonia. Anthropological Perspectives. Florida: University Press of Florida, 2007

Greene, Shane. Caminos y carretera. Acostumbrando la indigenidad en la selva peruana. Lima: IEP, 2009.

Guallart, José María. Entre pongo y cordillera: historia de la etnia aguarunahuambisa. Lima: Centro Amazónico de Antropología y Aplicación Práctica, 1990.

Guallart, José Maria. El vicariato de San Francisco Javier de Marañón: 50 años de una misión jesuita. Lima, CAAAP, 1997.

\footnotetext{
${ }^{68}$ David Stoll, "The Summer Institute of Linguistics and indigenous movements", Latin American Perspectives, 9.2 (1982): 91.

${ }^{69}$ Stoll hace referencia al fenómeno migratorio de los agricultores andinos que a partir de los años " 60 empezaban a ocupar sus tierras y construir pequeños espacios urbanos en las regiones amazónicas (David Stoll 91).
} 
La visión de la bandera. Memorias oníricas awajún sobre la construcción de una sociedad...

Larson, Mildred y Lois, Dodds. Treasure in clay pots: An Amazon people on the wheel of change. Person to Person Books, 1985.

Mader, Elke. Metamorfosis del poder: persona, mito y visión en la sociedad shuar y achuar (Ecuador, Perú). Quito: Editorial Abya Yala, 1999.

Krupa, Christopher, y David Nugent, (eds). State theory and Andean politics: New approaches to the study of rule. University of Pennsylvania Press, 2015.

Siverts, Henning. Tribal Survival in the Alto Marañon: The Aguaruna Case. Vol. 10. Copenhagen. Secretariat of IWGIA, 1972.

Surrallés, Alexandre C. En el corazón del sentido: Percepción, afectividad, acción en los candoshi, Alta Amazonía. Lima: Instituto Francés de Estudios Andinos, 2009.

Wallis, Ethel Emily. Tariri: My Story: From Jungle Killer to Christian Missionary. Hodder and Stoughton, 1966.

Winans, Roger. Gospel over the Andes: notes of Roger S. Winans. Kansas City, Beacon Hill Press, 1955.

\section{Capítulos de libros}

Priest, Robert. “I Discovered My Sin!” Aguaruna Evangelical Conversion Narratives”. The Anthropology of Religious Conversion. A. Buckser \& S.Glazier (eds). New York, Toronto, Oxford: Rowman \& Littlefield Publishers, 2003.

Romio, Silvia. "El viaje hacia la ciudad: caminos de vida, camino para el poder. La nueva forma del ritual de iniciación entre los Awajún (1930-1960)". Apus, Caciques y Presidentes. Estado y política indígena amazónica en los países andinos. Surralés, A., Espinosa, O., Jabin, D. (eds.).. Lima: IWGIA, 2016.

Romio, Silvia. "Los awajún contra Herzog. Uso del conflicto en la construcción del liderazgo indígena". Política y poder en la Amazonía. Estrategias de los pueblos indígenas en los nuevos escenarios de los países andinos. Correa, François, Surrallés, Alexandre et Espinosa, Oscar (eds.). Bogotá: Universidad Nacional de Colombia, 2016.

Taylor, Anne Christine. "Sick of History: Contrasting Regimes of Historicity in the Upper Amazon". Time and Memory in Indigenous Amazonia. Anthropological Perspectives. Fausto, Carlos y Heckenberger, Micheal (eds.). Florida: University Press of Florida, 2007.

\section{Artículos de revistas}

Barclay, Frederica. "Pactos entre pueblos indígenas y el Estado en la Amazonía peruana republicana”. Amazonía Peruana 32 (2019). 
Bignon, François. "La militarización de los Orientes peruanos y ecuatorianos (19331941)”. Amazonía Peruana XVI. 32 (2019).

Hendricks, Janet W. "Power and knowledge: discourse and ideological transformation among the Shuar". American Ethnologist 15. 2 (1988).

La Serna Salcedo, Juan Carlos. "Viviendo con el diablo en casa. La enfermedad, hechicería infantil y violencia entre los asháninka desde la perspectiva misionera adventista". Bulletin de l'Institut français d'études andines 40.1 (2011).

Nugent, David. "Building the state, making the nation: The bases and limits of state centralization in "modern" Peru". American Anthropologist 96.2 (1994).

Krupa, Cristopher, y Prieto Noguera, M. “Corpus Mysticum estatal o ¿cómo podemos pensar el estado en América Latina hoy?” Iconos 52.1 (2015).

Opas, Mina. "Dreaming faith into being: indigenous evangelicals and co-acted experiences of the divine". Temenos-Nordic Journal of Comparative Religion 52.2 (2016).

Robbins, Joel y otros. "Continuity thinking and the problem of Christian culture: Belief, time, and the anthropology of Christianity". Current anthropology 48. 1 (2007).

Robbins, Schieffelin y otros. "Evangelical conversion and the transformation of the self in Amazonia and Melanesia: Christianity and the revival of anthropological comparison". Comparative Studies in Society and History 56.3 (2014).

Romio, Silvia. "La voz de Dios y la respuesta awajún. El caso de la Iglesia Bíblica Awajún en el Alto Marañón (Amazonía Peruana)". Buletin del Instituto Francés de Estudios Andinos 47.3 (2018).

Rubenstein, Steven L. "Importance of vision among the Amazonian Shuar". Chicago Journal, Current Anthropology 53.1 (2012).

Stoll, David. "The Summer Institute of Linguistics and indigenous movements". Latin American Perspectives 9. 2 (1982).

Taylor, Anne Christine. "Remembering to forget: identity, mourning and memory among the Jivaro". Man New Series 28.4 (1993).

Taylor, Anne Christine. "Des fantômes stupéfiants: langage et croyance dans la pensée Achuar”, en L'Homme 33 (1993) : 126-128). 
La visión de la bandera. Memorias oníricas awajún sobre la construcción de una sociedad...

Taylor, Anne-Christine. "Devenir jivaro. Le statut de 1'homicide guerrier en Amazonie." Cahiers d'anthropologie sociale 2 (2006).

\section{Tesis, ponencias, documentos y otros}

Barclay, Frederica, and Equipo ODECOFROC. "Crónica de un Engaño. Los intentos de enajenación del territorio fronterizo Awajún en la Cordillera del Cóndor a favor de la Minería." Lima, Iwgia, 2009.

Favier, Irène. La convoitise des confins. Luttes foncières et redéfinition du national dans le Haut Marañón péruvien (1946-2009). Tesis de doctorado. Paris, Université de Paris VIII, 2014.

Instituto Lingüístico de Verano. Duik muunta pujuti augbatbau. Lima: Publicaciones ILV, 1992.

Ortiz Batallas, Cecilia de Lourdes. Shuar, salesianos y militares. La formación del estado en el sur-oriente ecuatoriano 1893-1960. Tesis de doctorado. Quito: FLACSO, 2019.

Priest, Robert. Defilement, Moral Purity and Transgressive Power: The symbolism of Filth in Aguaruna Culture. PhD thesis in Anthropology, Berkeley, University of California, 1993.

Romio, Silvia. "Suivre le chemin".: la construction de l'identité politique des Awajún d'Amazonie péruvienne (1920-1980). Tesis de doctorado. Paris : Ecole des Hautes Etudes en Sciences Sociales, 2017. 